\title{
Can Practical Wisdom Mitigate the Negative Effects of Rule-following and Hyper-codification
}

\author{
Ennio Lugli* , Federico Bertacchini \\ Department of Economics Marco Biagi, University of Modena and Reggio Emilia, Italy
}

Received July 9, 2020; Revised August 20, 2020; Accepted September 11, 2020

\section{Cite This Paper in the following Citation Styles}

(a): [1] Ennio Lugli, Federico Bertacchini, "Can Practical Wisdom Mitigate the Negative Effects of Rule-following and Hyper-codification," Universal Journal of Accounting and Finance, Vol. 8, No. 3, pp. 75 - 81, 2020. DOI: 10.13189/ujaf.2020.080303.

(b): Ennio Lugli, Federico Bertacchini (2020). Can Practical Wisdom Mitigate the Negative Effects of Rule-following and Hyper-codification. Universal Journal of Accounting and Finance, 8(3), 75 - 81. DOI: 10.13189/ujaf.2020.080303.

Copyright $\bigcirc 2020$ by authors, all rights reserved. Authors agree that this article remains permanently open access under the terms of the Creative Commons Attribution License 4.0 International License

\begin{abstract}
This article sets out to explain how practical wisdom, supported by rationality, can play a fundamental role in management and combat the main problems of rule-following and hyper-codification. The systematic use of Big Data, collected via the ever-increasing adoption of technology, has generated a large increase in the degree of standardisation of company procedures concerning not only physical and technical issues but above all decision-making. Applied to the solution of repetitive, easily codified problems, standardisation increases the level of efficiency, but when used for the resolution of complex problems it may partially, or even completely, preclude the pursuance of the common good. This may occur through the setting of rules which are not capable of fully describing reality, and their inappropriate use, which may lead, through their unthinking application, to a lack of morality, and even to the side-lining of earnings opportunities. We believe that practical wisdom is able to interact with necessary, unavoidable codification systems and rules to provide the right interface with circumstances, becoming a part of the decision-making process in its own right and not just a viewing lens for use retrospectively to verify whether the outcomes of decisions taken have been effective in pursuing the common good.
\end{abstract}

Keywords Practical Wisdom, Rule-following, Big Data, Wise-leaders

\section{Introduction}

In modern organisations, organisational and decision-making processes are increasingly managed by systems of rules intended to limit the degree of discretion granted to individual actors and reduce risks in business management. For companies, it is crucial for employees to follow common systems of organisational rules and policies, to ensure effective collective coordination [32]. However, these codification processes have reached extremely, if not excessively, high levels. Every single aspect of company life, especially within large organisations, is more or less directly controlled via procedural and behavioural codes. This extreme codification has deprived many company practices of subjectivity. The overriding belief is therefore that codification and efficiency/efficacy are strongly correlated. But how have we arrived at this excessive rule-following? The degree of integration between technology and the business world is now extremely high. Therefore, companies are able to access a huge mass of data. Access to these data and the analysis of the information they yield have enabled the implementation of much more effective business strategies than in the past. New corporate functions, such as Business Intelligence, have arisen specifically to study data analysis technologies, methods and systems [8]. This has generated an increasingly strong conviction in the business world that greater access to information can be translated into better results in all cases. The data collected and analysed are used not just for the implementation of strategies addressing the world outside the company itself, but also for the structuring of corporate practices to improve the productivity and 
efficiency of internal processes. The codification of activities, and thus the standardisation of some relationships, can be a successful strategy, as long as this practice does not completely absorb and restrict every aspect of individuals' discretionality. In fact, it is safe to assume that these data may be used in a virtually unlimited way in specific areas within the company (marketing area, management control, etc.); however, the logical approach underlying the codification of processes in these areas is not appropriate to the management of processes of an ethical and behaviour nature. In these contexts, it is impossible to separate the judgement of the individuals called upon to act from their personal values and the ethical frameworks they have built up in the course of their experience [25]. Excessive codification occurs when attempts are made to schematise and catalogue processes and relations which, by their very nature, intrinsically demand a contingent approach and analysis. We are, in fact, led to believe that the systems of codes and rules derived from the analysis of the huge amount of data we hold are able to provide us with almost exhaustive coverage and descriptions of all possible eventualities and hypotheses. However, just as a function tends towards its asymptote, codification will never be able to cover all real cases. This is because, even if we held information tending towards the infinite, we would still encounter situations in which the decisions to be taken would extend beyond this information, since they would refer to aspects of an ethical and moral nature. These codes do not promote reasoned behaviours and therefore do not contribute to the growth of the people called upon to act [20].

It is not a matter of bearing in mind a specific ethical or moral law when drawing up or preparing a code of rules; the problem is that it would never be possible to provide an exhaustive description of every possible case. The aim should be to use practical wisdom to apply people's ethics and morals to the codes in order to interface with an infinite number of situations that demand a specific, direct approach.

\section{Phronesis}

Very probably, Aristotle [2] was the first to develop a systematic understanding of what defines a wise person from a practical point of view. In book VI of the Nicomachean Ethics [2], Aristotle provides a classification of the dianoetic, or intellectual, virtues. He first describes the dianoetic virtues which exercise a theoretical scientific (epistemonikòn) faculty, because since the scientific virtues aim for knowledge of truth for its own sake, their sole objective is pure wisdom (sophìa). The scientific faculty is expressed in scientific knowledge (epistème), concerned with demonstrable facts, in intuitive reason (noùs), concerned with first principles, and in theoretical wisdom (sophìa), which is the synthesis of the two. He describes these as the intellectual virtues by means of which "we contemplate those things whose first principles cannot be otherwise" [2]. However, from a purely practical point of view, Aristotle describes these types of virtues as "useless", citing the fact that the philosophers Anaxagoras and Thales were generally considered to be knowledgeable but not wise [2]. Aristotle [2] goes on to present other intellectual virtues, which exercise the faculty of calculation (loghistikòn), a practice that includes the virtues of technical reason (téchne) and practical wisdom (phrònesis), both of which focus on matters related to human affairs, meaning specific circumstances or actual events that can be controlled, chosen, started, constructed, modified or developed in an exemplary manner. While téchne calculates the relationship of cause and effect in order to achieve the expected result, phrònesis focuses on the sorts of things conducive to living well in general, both for ourselves and for our communities [2,5]. As Aristotle [2] states, "we think Pericles and people like him are practically wise, because they can see what is good for themselves and what is good for people in general; and we consider household managers and politicians to be like this" [2].

It is also worth looking at the practical aspects of the wisdom of phronesis in the light of the distinction between it and Aristotle's other form of wisdom: sophia. For Aristotle [2], sophia is much closer to what we would probably recognize as the ability to implement logical and analytical skills, and is general in its application - unlike episteme, which is knowledge limited to a particular area of expertise. Therefore, while sophia might enable a person to understand general principles of cause and effect, phronesis is the form of wisdom which enables a person to act on the world for the common good. This also implies that phronesis exists in a world of uncertainty and ambiguity, where cause and effect are not necessarily clear, and it may not be possible to predict the outcome of an action or a decision with any degree of certainty.

Since it considers not only actual specificities but also both teleological and ethical aims, practical wisdom is much more than tactical cunning or intelligence [2,30]. Its ethical component makes practical wisdom the highest of the intellectual virtues. It represents not the "right" way of doing things in a particular community, but the ethically good action which a wise person should undertake. Although practical, technical reason differs from practical wisdom in that means of production are finalized on products, while phrònesis embraces its own end, action in accordance with practical wisdom [2]. To understand whether an action has been performed in accordance with practical wisdom, it is not sufficient to observe the final outcome or consequence of what a person did; Rather, we need to see how and why the person did what they did in that particular situation [7]. Ethical evaluations must be located and contextualised. According to Aristotle [2], 
phrònesis is the ability to act well in specific situations. By placing the emphasis on practice, phronesis forges a direct link between ethics and actions in contextualised situations: phronesis is bound up with action, and action concerns the particulars [2].

Aristotle casts doubts on the usefulness of knowledge when it is not correlated with actions, arguing that a person can only become good by doing good. The insufficiency of knowledge alone and the impossibility of becoming good without actions are exemplified by the case of the patient who does not follow his doctor's instructions [2].

Aristotle maintains that a person's virtue derives from his or her habits: moral virtue is the result of habit, and so it is that moral virtue got its name [ethike] by a slight alteration of the term habit [ethos] [2]. Virtue is therefore intrinsic to the human being and occurs naturally, without the application of ethical rules. A habitual action in itself is not without meaning, since a virtuous person acts rightly in every particular circumstance, knowing what is the right action to take. Reason and the desire for action are incorporated in it and are not its cause. A good action cannot be described independently of the situation in which it is performed, or generalised in universal rules or laws, because that would separate knowledge from actions and the rule from the contextual circumstances. Returning to the example of the doctor, Aristotle [2] underlines that the doctor will not consider health in absolute terms, but rather health as related to people, and, even more specifically, the health of his individual patients [2].

A good doctor knows how to treat every single patient on the basis of his knowledge of medicine in general and, above all, his practical experience of actually treating patients [23]. Therefore, ethics must concentrate on activities in a specific situation, since no two situations are identical. Aristotle [2] maintains that generally applicable ethical rules are an impossibility and does not put forward any decision-making procedure, code or algorithm, because circumstances change constantly. Moreover, if we were forced to obey preset rules, our actions would no longer be virtuous because, according to Aristotle, an action cannot be virtuous unless it is voluntary. Every form of external pressure therefore reduces the potential for virtuous actions. The resulting actions may still have a good cause or consequence, but cannot be considered virtuous. Ethical considerations cannot be tied to specific principles, since we should be able to behave differently in different situations. In practice, the ethical decision-making process always takes place in particular circumstances [23]. An action's goodness lies within itself, with no separation between the act and the deliberations from which it results.

Phronesis requires first and foremost willingness to accept and understand every particular situation just as it is, secondly, theoretical knowledge and experience to choose and apply the right means, and thirdly, excellence of character to define the right ends [1,18,19]. The Aristotelian concept of practical wisdom can be seen as a connection between mind and body, since the habit of virtue is the habit of thought and action [26].

\section{Practical Wisdom within the Firm}

It is difficult to establish what practical wisdom is and how it can be perceived within a firm. In a world saturated with rules and data, there is no room for their pro-active interpretation and understanding. Systems of rules and procedural codes do not allow any scope for contingent interpretations and hypotheses. It appears that the application of these systems is a necessary precondition for the correct functioning of any modern organisation. However, codes and rules do not allow for subtle distinctions: they represent the world in just black and white, although the social context within which businesses operate is full of shades of grey [29]. Constructing and expressing interpretations of the surrounding environment is of fundamental importance both for individuals and for organisations overall [9]. These are some of the reasons why practical wisdom is becoming more and more important in management literature. From the conceptual point of view, in fact, practical wisdom's field of application is very broad, and it may thus include various aspects of a company's organisation [4]: leadership [7], entrepreneurship [12], decision-making [22], problem-solving [24], HR management [10] and the education of managers [3]. In spite of its diverse contexts of theoretical application, the level of development of practical wisdom as a positive within company organisations is still very limited. In fact, it presupposes that individual actors will acquire direct, "hands-on" experience. The development of a "ready-made" solution, dictated directly by company rules and codes, cannot be defined as experience. However, only the top management within a company's hierarchy is granted the opportunity to gain this "hands-on experience". As we work downwards through a typical hierarchy, two things happen simultaneously: the number and intensity of the rules with which players have to comply increases the discretionary freedom granted to the individual roles/people decreases.

Although very common, this approach does not aid the correct professional and experiential growth of the people within the organisation; it merely suffocates the capacity for critical thought of the individuals called upon to act. Paradoxically, what could be excellent ideas from the theoretical and practical point of view might run the risk of being completely suffocated or obscured by the company's organisation itself, preventing their correct evolution and application [13].

But how can we expect managers intended for key roles within the company in the future to be wise leaders if they have been constricted by rigid systems of rules and codes 
throughout their previous career/training?

It might be argued that managers are able to learn the "modus operandi" in the various situations by observing and understanding the behaviors of their superordinates (whose decision-making power is also restricted by rules and codes). However, the value of this learning process might be meagre, since every event and every person are unique, and it is thus difficult to pick up the values and wisdom necessary to interface with the different situations that will occur in the future by mere imitation [14].

These mechanisms leave wisdom, in the Aristotelian sense, out in the cold. The wise leader is the person able to take the best decision within a given context, on the basis of their experience and the values acquired through it. He or she is able to understand and effectively interpret their context and take decisions perfectly appropriate to the situation analyzed. The systems of rules adopted within firms make the development of leaders of this kind particularly difficult.

The universal adoption of codes of ethics during the last few years is emblematic here. They also consist of a set of regulations, rules and values which must be followed and complied with by the people working for the firm. However, these codes have had varying degrees of success and have been criticized for a number of reasons: they do not give consideration to the moral growth of the people involved, and often focus only on compliance with the values they promote, rather than their real dissemination within the organisation [27]. Interestingly, one example of their beneficial effects is provided by a world apparently very remote from the modern concept of the firm. Within Benedictine monasteries, the ancient code of rules established by St Benedict is still in use today, and its interpretation and understanding (within the various situations) actively contributes to the moral, ethical and experiential growth of the individual members and of the monastic community as a whole [20].

This simple example helps us to understand the profound difference that may lie between:the correct application of a fairly concise system of rules that does not claim to be exhaustive and the Utopian desire for completeness that surrounds the systems of rules and codes found in modern business organizations.

Chance presents infinite possibilities. In this sense, a company is not unlike any living being: infinite possible opportunities, infinite possible risks and infinite gradations within the same opportunity or risk. Attempting to circumscribe this context in absolute terms is not just absurd: it is impossible. No rule, even the most detailed, can be effective on occasions which involve interaction between people [29]. Practical wisdom helps firms, and above all the people who belong to them, to deal with the infinite possibilities which chance "offers". Every possibility and every occasion need a unique, individualized interface.

This article has two aims: on the one hand to attempt to understand the importance of interpretation within the systems of rules set by companies; and on the other hand, to understand the need for these codes to implicitly envisage the opportunity for value development on the part of the people who interface with them. A system of this kind would be capable of developing virtuous leaders, able to provide wise responses with the various situations with which they are required to interact. In fact, a "wise response" does not only include the part derived from knowledge (material, financial or technical in general): it must also include the right mix of moral and practical virtues [15].

The effective dissemination of practical wisdom amongst the members of a company organization would not only be able to create good managers, but would also enable the development of more profitable relations with stakeholders, and help the company to operate more effectively within its competitive environment. This would generate the ability to respond to market opportunities ahead of time in the short term, while simultaneously forming a competitive advantage in the long term, because decisions would be made with consideration of the various contingent issues, with the constant aim of the best interests of all the stakeholders involved [16].

However, not much space is given to the interpretation of contingent situations in modern business practice. The space within which decisions can be taken is extremely tight, circumscribed by systems of rules. In this context, practical wisdom is not developed and the education of wise leaders is prevented by the organization itself, since it does not create an environment capable of developing wise choices [6].

To conclude, if we assume that practical wisdom is strictly interconnected with experience, we cannot expect an organization's members to develop this virtue if the organization's own structural approach only allows the acquisition of experience strictly limited and guided by the codes of rules it enforces.

\section{Practical Wisdom and Wise Leaders}

As already mentioned, the development of practical wisdom is not encouraged or facilitated by the way company structures operate, even though it is of crucial importance for the education of wise leaders $[11,25]$.

We are led to believe that people only need the right tools and the right rules to be able to perform their tasks in the best possible way.

Aristotle agreed that rules were important, but he was equally sure that they were not enough. The need is for people capable of applying "practical wisdom" to decide how to interpret and apply the rules. Sometimes, rules require adaptation. Institutions need to be changed in order to achieve their goals. 
So working on these assumptions, which are the factors lead company organizations in general not to encourage the development of practical wisdom? One possible answer lies in the corporate culture fostered by business schools. Universities teach future managers about "agency theory" and the need to control people to prevent "opportunist behaviors" [13]. How can we expect that in their future careers these students will organize and work in businesses which encourage the development of practical wisdom? As already explained, acting in accordance with practical wisdom means being able to take decisions on the basis of the experience, values and knowledge possessed by the person called upon to act at a given moment; moreover, these decisions must be intended not to achieve just any goal, but must be aimed at pursuing the common good. Therefore, on the one hand future managers are told to be on their guard against unethical behavior on the part of the people working alongside them, while on the other practical wisdom urges action intended to achieve the common good. It is easy to understand that these factors are conflicting, at least in part. In fact, the systems of rules introduced to protect against the risk of opportunist behaviors indirectly preclude the possibility of developing practical wisdom. Contingent situations are universalized in order to define a common, standardized, and above all controllable approach. However, people capable of acting on the basis of practical wisdom do not require such strict control, since they take decisions for the common good on the basis of the specific situation.

Company structures, dynamics and mechanisms are designed to pursue and support the strategies intrinsic to managerial theories. In the most extreme definition, there is no space for personal interpretations or inclinations, work is defined and controlled, and the space for subjective inputs is limited and supervised.

At the same time, we must underline that company practices and procedures are fundamental for increasing efficiency within organizations. They speed up the analysis and handling of the various situations which may arise. How can the efficiency of consolidated procedures be reconciled with the development of practical wisdom? What makes a wise leader, and why are they important? What benefits might practical wisdom provide?

Practical wisdom is developed through direct experience and activities. Company practices and procedures must not be jettisoned, but must be combined with times and spaces where people can work "freely", outside the rigidity of the consolidated procedures. It is important to appreciate that the possible benefits of this approach may be to the advantage of both the company and its workers. The former would see the emergence, within itself, of new ideas and projects capable of improving the organization and increasing its value. The latter would be granted the opportunity to say what they think, and enjoy a more inclusive, stimulating working environment. This might lead to the reconsideration and rewriting of consolidated but obsolete company practices. Innovative projects which have not yet occurred to the top management might evolve. Workers' motivation would increase, as they would be able to receive feedback on their ideas, understand any mistakes and gain experience through discussion. It is important to emphasize that there is no "one size fits all" solution for every type of firm or organization. Different organizations might fulfil these needs with completely different procedures and rules.

One tool usually adopted is the ESS - Employees Suggestion System. This tool is a mechanism that enables employees to express their ideas and suggest solutions to improve the organization within which they work [21]. The system has evolved over time to assume different forms and modes [17]. However, it is only a starting-point and an example of how a process of the inclusion, growth and valuing of the company's employees can be activated. The development of practical wisdom cannot only be supported by practices of this kind, but the construction of a working environment focused on listening and inclusion helps to develop the necessary foundations for the creation of wise leaders. To answer the initial question, the integration between formalized procedures on the one hand and practical wisdom on the other can be achieved by different methods, which must be developed and interpreted as appropriate to the specific context. However, it is fundamental to encourage the adoption of practices and tools able to facilitate the development process of practical wisdom. The aim must be to promote the widespread dissemination of this practical wisdom, so that it is no longer perceived as a separate entity from procedures, but rather as an essential input for analysis of everything relating to the organization. Practical wisdom must therefore be viewed not as a tool to be adopted, but as a characteristic to be cultivated. Any tool or mechanism capable of aiding its development should be studied and adopted.

The creation of wise leaders also starts here. Companies, and therefore society, need leaders capable of facing the new challenges posed by continual technological and sociological evolution, which make the sustainability of the strategies adopted more and more complex [28]. These leaders will be increasingly called upon to weigh their decisions in order to balance their ethical and economic dimensions. A wise leader can thus be defined as a person able to take decisions that are effective from both the technical/economic and the ethical/moral points of view, for the pursuance of the common good.

\section{Conclusions}

The dissemination of practical wisdom might therefore offer us more balanced choices. The people called upon to decide would have a greater ability to perceive and consider a global view of their actions, and thus of their 
effects across time and space, and therefore to adopt a holistic approach. This would take place at every level within the organization, influencing both simple processes within a company and the environment which surrounds the organization, thus establishing a flow of positive feedback between stakeholders. The end result would be the creation of a win-win system, to the advantage of all the players involved. Practical wisdom would therefore improve both internal and external relations, favor managers' growth paths, and help the various companies to grow with respect for the common good. However, this wisdom cannot emerge without a suitable, favorable environment able to include, listen and understand.

\section{REFERENCES}

[1] Arjoon S., "Reconciling situational social psychology with virtue ethics", International Journal of Management Reviews, vol. 10, n. 3, pp. 221-243, 2008. https://doi.org/10.1111/j.1468-2370.2007.00216.x

[2] Aristotle, “Nicomachean Ethics”, (R. Crisp, Trans.), Cambridge: Cambridge University Press, 2004.

[3] Bachmann C., "Can practical wisdom be taught in business schools? An inquiry-based learning approach for management education”, in Blessinger P., Carfora J. M., Inquiry-based learning for the arts, humanities, and social sciences: A conceptual and practical resource for educators, Emerald Group Publishing Limited, 2014, pp. 277-302.

[4] Bachmann C., Habisch A., Dierksmeier C., "Practical wisdom: management's no longer forgotten virtue”, Journal of Business Ethics, vol. 153, no. 1, pp. 147-165, 2018. https://doi.org/10.1007/s10551-016-3417-y

[5] Beabout G. R., "Management as a domain-relative practice that requires and develops practical wisdom”, Business Ethics Quarterly, vol. 22, no. 2, pp. 405-432, 2012. https://doi.org/10.5840/beq201222214

[6] Beshears J., Gino F., "Leaders as decision architects: structure your organization's work to encourage wise choices”, Harvard Business Review, vol. 93, no. 5, pp. 52-62, 2015.

[7] Bragues, G., "Seek the good life, not money: The Aristotelian approach to business ethics", Journal of Business Ethics, vol. 67, no. 4, pp. 341-357, 2006. https://doi.org/10.1007/s10551-006-9026-4

[8] Chen H., Chiang R. H. L., Storey V. C., "Business intelligence and analytics: From big data to big impact", MIS Quarterly: Management Information Systems, vol. 36, no. 4, pp. 1165-1188, 2012. https://doi.org/10.2307/417035 03

[9] Daft R. L., Weick K. E., “Toward a model of organizations as interpretation systems", Academy of Management Review, vol. 9, no. 2, pp. 284-295, 1984. https://doi.org/10.5465/amr.1984.4277657

[10] DeNisi A. S., Belsito C. A., "Wisdom and human resource management”, in Kessler E. H., Bailey J. R., Handbook of organizational and managerial wisdom, Thousand Oaks, CA: Sage Publications, 2007, pp. 261-273.

[11] Ding W., Choi E., Aoyama A., "Relational study of wise (phronetic) leadership, knowledge management capability, and innovation performance", Asia Pacific Management Review, vol. 24, no. 4, pp. 310-317, 2019. https://doi.org/10.1016/j.apmrv.2018.10.005

[12] Dunham L., McVea J., Freeman R. E., "Entrepreneurial wisdom: Incorporating the ethical and strategic dimensions of entrepreneurial decision-making”, International Journal of Entrepreneurship and Small Business, vol. 6, no. 1, pp. 8-19, 2008. https://doi.org/10.1504/IJESB.2008.017386

[13] Ghoshal S., "Bad management theories are destroying good management practices", Academy of Management Learning \& education, vol. 4, no. 1, pp. 75-91, 2005. http://dx.doi.org/10.5465/AMLE.2005.16132558

[14] Grint K., "Learning to lead: can Aristotle help us find the road to wisdom?”, Leadership, vol. 3, no. 2, pp. 231-246, 2007. https://doi.org/10.1177/1742715007076215

[15] Intezari A., Pauleen D. J., "Management wisdom in perspective: Are you virtuous enough to succeed in volatile times?”, Journal of Business Ethics, vol. 120, no. 3, pp. 393-404, 2014. https://doi.org/10.1007/s10551-013-1666-6

[16] Intezari A., Pauleen D. J., “Conceptualizing Wise Management Decision -Makigagounded Theory Approach”, Decision Sciences, vol. 49, no. 2, pp. 335-400, 2018. https://doi.org/10.1111/deci.12267

[17] Lasrado F., “An Overview of employee suggestion schemes: The past, present and the future", Skyline Business Journal, vol. 8, no. 1, pp. 15-22, 2012.

[18] Mele' D., “Integrating personalism into virtue-based business ethics: The personalist and the common good principles”, Journal of Business Ethics, vol. 88, no. 1, pp. 227-244, 2009. https://doi.org/10.1007/s10551-009-0108-y

[19] Mele' D., "Practical wisdom in managerial decision making”, Journal of Management Development, vol. 29, no. 7, pp. 637-645, 2010. https://doi.org/10.1108/02621711011 059068

[20] Mercier G., Deslandes G., “There are no Codes, Only Interpretations. Practical Wisdom and Hermeneutics in Monastic Organizations, Journal of Business Ethics, vol. 145, no. 4, pp. 781-794, 2017. https://doi.org/10.1007/s105 51-016-3055-4

[21] Milner E., Kinnell M., Usherwood B., "Employee suggestion schemes; a management tool for the 1990s?”, Library Management, vol. 16, no. 3, pp. 3-8, 1995. https://doi.org/10.1108/01435129510083008

[22] Moberg D. J., "Practical Wisdom and Business Ethics: Presidential Address to the Society for Business Ethics Atlanta, August 2006”, Business Ethics Quarterly, vol. 17, no. 3, pp. 535-561, 2007. https://doi.org/10.5840/beq20071 7336

[23] Morse J., "Who is the ethics expert? The original footnote to Plato”, Business Ethics Quarterly, vol. 9, no. 4, pp. 693-697, 1999. https://doi.org/10.2307/3857946

[24] Mumford M. D., Zaccaro S. J., Harding F. D., Jacobs, T. O., Fleishman E. A., "Leadership skills for a changing world: 
solving complex social problems”, The Leadership Quarterly, vol. 11, no. 1, pp. 11-35, 2000. https://doi.org/10 .1016/S1048-9843(99)00041-7

[25] Nonaka I., Takeuchi H., “The wise leader”, Harvard Business Review, vol. 89, no. 5, pp. 58-67, 2011.

[26] Nyberg D., "The morality of everyday activities: Not the right, but the good thing to do", Journal of Business Ethics, vol. 81, no. 3, pp. 587-598, 2008. https://doi.org/10.1007/s10551-007-9530-1

[27] Painter-Morland M., “Questioning corporate codes of ethics”, Business Ethics: a European Review, vol. 19, no. 3, pp. 265-279, 2010. https://doi.org/10.1111/j.1467-8608.20 10.01591.x

[28] Roos J., "Practical wisdom: making and teaching the governance case for sustainability”, Journal of Cleaner Production, vol. 140, part 1, pp. 117-124, 2017. https://doi.org/10.1016/j.jclepro.2015.10.135

[29] Schwartz B., "Practical wisdom and organizations", Research in Organizational Behavior, vol. 31, pp. 3-23, 2011. https://doi.org/10.1016/j.riob.2011.09.001

[30] Sison A. J. G., "The moral capital of leaders: Why virtue matters”, Cheltenham, England: Edward Elgar Publishing Limited, 2003.

[31] Sternberg R., “A systems model of leadership - WICS”, The American Psychologist, vol. 62, no. 1, pp. 34-42, 2007. https://doi.org/10.1037/0003-066X.62.1.34

[32] Tyler T. R., Blader S. L., "Can businesses effectively regulate employee conduct? The antecedents of rule following in work settings", Academy of Management Journal, vol. 48, no. 6, pp. 1143-1158, 2005. https://doi.org/10.5465/amj.2005.19573114 